\title{
Theory and Practice of Design and Making of Microlecture
}

$$
\text { QU Qinghong }{ }^{1, a,{ }^{*}}, \text { GAO Feng }{ }^{2, b}
$$

\author{
${ }^{1}$ Media College, Baicheng Normal University, Baicheng 137000, China \\ ${ }^{2}$ College of Physics and Electronic Information, Baicheng Normal University, Baicheng 137000, \\ China
}

aemail:quqinghong@163.com, bemail:gaof317@163.com, *corresponding author

\begin{abstract}
Keywords: microlecture video; making processes; making ideas
\end{abstract}
\begin{abstract}
With the continuous development of network technology and the advance of the new curriculum reform, great changes have taken place in the classroom education of our school. As a new teaching method, microlecture has been widely used in many subjects. This paper discusses mainly the characteristics, design and making processes and making ideas of microlecture, hoping to be useful for the work of relevant education and teaching staff.
\end{abstract}

\section{Introduction}

With a "small video" as the carrier, microlecture integrates the teaching content and related teaching material design, courseware, teaching reflection, practice test and student feedback, teacher comments and other supplementary teaching resources into a whole, its purpose is to improve students' learning interest, cultivate students' autonomous learning ability, and ultimately improve the efficiency of classroom teaching. At present, many schools have introduced the microlecture into the class, that can enhance the efficiency of classroom teaching to a certain extent, but some teachers in home have some deviations in understanding the microlecture and some problems appear in the microlecture video design. Some ideas and methods about the design and making of microlecture will be briefly introduced in this paper.

\section{The Connotation Characteristics of Microlecture}

Professor LeRoy A. McGrew of University of Northern Iowa in America put forward the design thought of the 60s course in 1993, T. P. Kee of British Napier University proposed the teaching method of a minute speech in 1995, they both were the earliest idea of microlecture. In 2008 David Penrose of San Juan College in the United States explicitly put forward the concept of micro course, in the current stage, under the background of network communication rapid development microlecture as a new teaching method has been spreaded quickly. In 2011, the microlecture collection assessment activities were initiated in Foshan, Guangdong for the first time, and then the microlecture in the country began to be applied. Microlecture, as a form of informatization teaching resources, not only can be used as an informal learning resource for students to preview before class and review after class, but also can be used as a formal teaching resources and has great potential. Through the application of this teaching form, we can summarize the characteristics of the microlecture to be educational, purpose, interest and sharing attribute. First of all, microlecture is a kind of online education resource whose main purpose is to solve the practical problems existing in the teaching of various subjects, so educational attribute is the most important characteristic; secondly, the microlecture video needs to be combined with the actual teaching content and teaching activities in the production, and must have a very clear teaching purpose and can achieve the goal of teaching in the shortest possible time; thirdly, in order to attract students' learning enthusiasm, microlecture should have a stronger interest and can actively participate in the learning activities; finally, sharing is an important feature of the microlecture, teachers should use modern Internet technology to strengthen the communication between each other, cancel browsing restrictions, realize the sharing of teaching information, expand the teaching resources. 
Under the network environment, the core of microlecture is the micro video, in the network learning platform video, courseware, learning guidance, teaching reflection, practice, test and so on are combined into a knowledge system structure. With different disciplines, different learning environment, the composition elements may have some differences, in general, it is composed of microlecture video, teaching courseware, learning guidance, learning introduction, problem solving, reviews and so on several factors.

\section{The Analysis of the Making Process of Microlecture}

In fact, the microlecture makes the systematic subject knowledge refine into a short, relatively complete structure the fragment, the microlecture can be used in the collective teaching, but also can be applied to the individual learning of students outside the classroom. The design and making process of microlecture will be introduced as follows.

Topic Selection. When using the microlecture teaching, teachers need to aim at a specific core concept, separate knowledge points or teaching activities and so on to make a clear teaching goal, and then according to this teaching goal teachers need to choose a teaching content and ensure all the contents with a clear explanation in a relatively short period of time to attract the attention of students, so that they can grasp the knowledge points, so the microlecture topic selection is very important. Under normal circumstances, the teachers take extraction of the key and difficult part of the teaching to carry out a detailed answer. The contents of mircolecture have many forms which mainly include the knowledge explanation, the knowledge expansion summary induction, the teaching material interpretation, the teaching experience exchanges and so on. On this basis, the topic selection of microlecture must be practical, in the design of microlecture teachers should carefully observe the learning status of the students, understand the learning psychology of students, consider the actual situation of their study and increase the fun of video to attract students' attention and enhance students' interest in learning and improve the efficiency of classroom teaching based on ensuring the quality of video teaching. In addition, when using the microlecture video teachers must make a reasonable arrangement according to the actual teaching contents, and the time of microlecture video can not be too long, the best one is ten minutes or so, for ensuring students in a very short period of time to master the knowledge points that are explained in the video. Some topics are not obvious, and relatively simple knowledge contents do not need to be developed into microlecture, so as not to increase the burden on the management system of microlecture, meanwhile wasting the time and effort of teachers.

The Teaching Design. In the process of microlecture design, first of all, we need to analyze the characteristics of students' learning, the teaching task and content of the course and determine a clear teaching goal, then according to the specific teaching content determine the type of microlecture and teaching strategies, methods, finally design video cases, teaching process, teaching materials, evaluation feedback mechanism and so on. In the design process of the video, the microlecture should as far as possible reduce the cognitive load of students, make theme clear and contents dapper, try to organize the teaching content in a relatively short period of time, for ensuring the process of teaching vivid to reduce students' learning pressure. After the video learning completed, the practical learning situations of students should be also consolidated. Generally speaking, the consolidation process is achieved through after-school practice, teachers can add some choice questions and open questions in supporting materials of microlecture video to let the students practice, especially the open exercise training results better, and in order to avoid excessive burden on students, the amount of exercise should not be too much.

The Video Making. The core of the microlecture is video, however teaching forms to take, microlecture should ensure the teaching process complete and short. Whether the introduction of teaching situation, the raise teaching problems or the arrangements of teaching activities, in order to attract the attention of students and let the students as much as possible memorize all the microlecture contents, teachers need to ensure teaching subject be novel and interesting, such as the form of import settings doubt or some phenomena and case in daily life of the students, to lead to the theme. The explanation of the microlecture should always focus on the theme and highlight the 
focus of teaching to reduce the student's study burden. In order to avoid the interference of external environment factors for students in the learning process, teachers can also take corresponding measures to enable students to always maintain a certain interest in learning content, such as outstanding presentation of learning content, the removal of unnecessary decoration.

Auxiliary Materials. The introduction to microlecture teaching contents, practice tests, teaching reflection, expert comment and so on are all auxiliary materials which are of great help to improve the efficiency of teaching, so the teachers should also pay attention to the preparation of this part of the content, but the content is not need exhaustive, teachers should select suitable parts according to the actual teaching content and the auxiliary materials should not be too redundant.

Uploading and Feedback. After the completion of microlecture video and auxiliary materials, they need to be uploaded to the campus network or the corresponding network environment, so that they can really play its role in teaching. At present, there are two kinds of network platform related to microlecture, one is the platform built for the micro lesson contest, the other is a comprehensive network learning platform. Overall, there is no the special perfect network learning environment built for micro teaching characteristics, therefore, the relevant education researchers also need to discuss more in this regard.

Evaluation and Modification. The evaluation of microlecture should include three aspects, educational evaluation, technical evaluation and evaluation of application effect. Educational evaluation mainly evaluates teaching target, teaching content, teaching method and so on, the good microlecture video should meet the following criteria: the clear learning object and teaching goal, prominent theme, proper layout, complete knowledge, novel form, vivid interesting explanations of the content, the appropriate number of learning resources, the good enlightening practice after class; Microlecture technology refers to that in the production of microlecture video, the technical standards of resolution and stream speed are in accordance with the relevant norms, layout coordination of video, reasonable collocation of courseware content, The related auxiliary material conforms to the technical specification, the form is diverse, the content complete, the microlecture platform can provide the user to search, browse, upload, information prompt, online or offline communication function and so on; the evaluation of the application effect of microlecture is mainly reflected by the user evaluation, click rate, the number of times and so on.

\section{The Making Idea of Microlecture}

At present, there are mainly five making methods about microlecture video, teaching video, screen recording, multimedia explanation, animation explanation, video clips, which are detailed in this paper.

The Type of Teaching Video. Using the camera, recording and broadcasting systems device to record the demonstration and teaching process of teachers, the micro video is called teaching video. The place of teaching activities is not restricted in the classroom or somewhere, but it must be neat, teachers must prepare lessons seriously.

The Type of Screen Recording. The screen recording is that by the computer software, multimedia courseware and other teaching tools, teaching content will be displayed in the computer screen directly, teachers explain the teaching content looking at the computer, or by drawing board, touch screen teaching content will be written on a computer monitor, and then use the recording screen software to record the teaching process, complete the entire video recording process. This video making method is very simple, teachers do not need to master too much professional knowledge of the computer, so having a higher degree of popularity. However, the quality of the video recorded by this method is difficult to ensure that requires teachers had better be able to carry out the recording in relatively quiet place in the school or other. When the teacher explains the teaching content, it should be smooth and natural, with the multimedia courseware to display teaching content in the screen.

The Type of Multimedia Explanation. When using multimedia to explain, the teaching contents are displayed through text, graphics, sound and other forms, and then are recorded by the recording screen software. Multimedia courseware quality will directly affect the quality of the 
video, so we must ensure that the picture is clear, sound and picture synchronization. Teachers can record the commentary in advance, and then through a certain technical method cut off the noise and the wrong places, this making method is relatively difficult, high quality micro lesson video can be produced using this method.

The Type of Animation Explanation. For the type of animation explanation, it is made by two-dimensional animation software, and through the vivid and interesting animation explain the teaching content, it is able to attract the interest of students and the teaching effect is better. But it is more difficult and trouble to make this type of video, teachers must collect more painting material.

The Type of Video Clip. The higher quality microlecture video is made by a video clip, in the process firstly teachers do the complete process of teaching, and secondly the post editing personnel carry out later stage compilation through the computer screen, voice, music, animation and other ways, finally the video is completed. This method is difficult and with high cost that need for detailed planning on the teaching design before the video, but the video quality is excellent.

\section{Summary}

Applying microlecture to do the actual teaching breaks through the traditional "Duck-stuffing" type of teaching mode, but at present, there are still some problems in the making and application of the microlecture video, which hinders the improvement of the efficiency of classroom teaching. So teachers must have a correct understanding of the use methods and making approach of microlecture, and reasonably use the microlecture video in the teaching process, improve the teaching quality.

\section{Reference}

[1] Meng Xiangzeng, Liu Ruimei, Wang Guangxin. The Theory and Practice of the Design and Construction of Microlectures [J]. Journal of Distance Education, 2014, (6):24-32.

[2] Xiao Li-zhang, Luo Jin. Micro video development direction of the micro teaching in university study [J]. Journal of Juamjusi Education Institute, 2015, (6):201-203.

[3]LI Hai-ying. The New Development Trend of "Micro Video Class" Teaching Information Resources in College Education [J].Value Engineering, 2014, (12):282-283.

[4HU Tie-sheng, ZHOU Xiao-qing. Current Situation Analysis and Development Strategies of the Micro-lecture Construction in Universities [J]. Modern Educational Technology, 2014, 24(2):5-13.

[5] ZHOU Bing-feng, XIE Xin-shui, LIU Xing-qi. Teaching Elements and Effect Evaluation of Micro-courses in University [J]. Modern Educational Technology, 2015, 25(9):30-36. 